\title{
Simulation Analysis of a Compound Investment Strategy for Mutual Funds: A Case Study on an Investment Trust Company
}

\author{
Jen-Ying Shih and Wei-Cheng Chiang
}

\begin{abstract}
This study adopted a simulation analysis based on back-testing historical data to evaluate the performance of a compound investment strategy which was proposed by a securities investment trust company for suggesting its customers in mutual fund investment. The compound strategy requires investors to choose a source-fund and a sub-fund or a set of sub-funds which have negative correlations or low correlations with the source-fund in their portfolio. Then we examined the performance of the strategy under three scenarios of past stock market in Taiwan, including A) TAIEX index initially decreasing then increasing, B) TAIEX index initially increasing then decreasing, and C) TAIEX index in long-term bullish trend. We compared the performance of the strategy with the following four benchmarks: 1) TAIEX index performance, 2) the performance of lump-sum (LS) investing approach in source-fund, 3) the performance of LS investing approach in sub-fund, and 4) the performance of dollar-cost averaging approach for sub-fund. The result shows that the compound strategy outperforms the benchmarks in two market scenarios with the feature of turning point.
\end{abstract}

Index Terms-Compound investment strategy, dollar-cost averaging, lump-sum, mutual fund.

\section{INTRODUCTION}

With financial deregulation, financial investment concepts have become popular in individuals; therefore, financial institutions have proposed lots of financial commodities and services for customers in assisting their financial planning. Investors thus have a lot of choices in investments [1], including stocks, bonds, mutual funds, derivatives, insurance, structured notes, etc. Among them, mutual fund is one of early development and highly acceptable investment commodities in Taiwan (see Fig. 1). The possible reasons are summarized as the following: 1) mutual fund is an investment portfolio which can diversify its investment risk by investing in a basket of financial commodities, such as stocks, bonds or derivatives; 2) flexible personal budgets for investments; and 3) involvement of professional managers in investment decisions. For meeting the demand of investors with different risk preference, financial institutions have proposed a variety of mutual funds, including growth stock funds, bond funds with different credit rating levels, balanced funds, exchange traded fund (ETF), etc.

Manuscript received September 20, 2017; revised Novmeber 16, 2017.

Jen-Ying Shih is with the Graduate Institute of Global Business and Strategy, National Taiwan Normal University, Taipei 10610, Taiwan (e-mail jyshih@ntnu.edu.tw).

Wei-Cheng Chiang is with the Fuh Hwa Securities Investment Trust CO. LTD, Taipei 104, Taiwan (e-mail: davidchiang@fhtrust.com.tw).

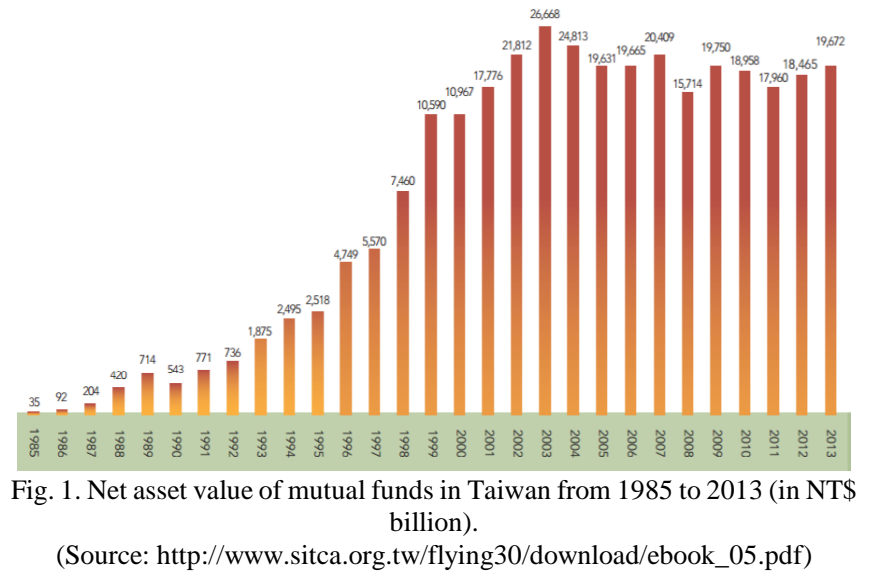

However, for individuals who have little knowledge of investment or who can only put limited efforts on investment, making decisions from lots of alternative funds may cause the following problems. The problem may be missing the timing of in-and-out of financial markets, the misunderstanding of individual risk preference, the greed of the individual or improper marketing tactics of commissioners, which have incurred a great loss on investors.

Based on the aforementioned problems, a securities investment trust company (Fuh Hwa Securities Investment Trust Ltd., hereafter the case company) proposed a compound investment strategy for its customers in investing mutual funds. The compound strategy is composed of lump-sum (LS) investing approach and dollar-cost averaging (DCA) approach in financial planning.

LS method is adopted in the following scenarios: As investors judge the financial market will be a bull market with high level of confidence, then they make a LS investment in the financial commodities which may help them benefit from such forecasting [2], [3]. However, if investors make the incorrect forecasting in choosing the target mutual funds or investment timing, then they could suffer a large loss by this method.

Hence, some researchers proposed DCA method to conquer the preceding problem [4]-[6]. DCA approach is a process of making a regular deposit in specified mutual funds at a regular time interval. The merits of this method are as follows: 1) the method can diversify investment risk by timing diversification during the period of the investment life cycle; 2) the flexible investment plan with relatively small amounts of each investment can reduce investors' financial pressure and develop disciplined long-term investment plans [3], [5], [6]. As Taiwan's economy was in the period of 1982 to 2012, on average, every 13 months would occur a financial 
fluctuation which let TAIEX index (Taiwan stock exchange capitalization weighted stock index) generate a loss of $29.58 \%$. Among them, eight events led to the investment loss greater than $40 \%$, especially the occurrence of global financial crisis, such as sub-prime financial tsunami in 2008, or national tax issues on securities market, such as reinstating capital gain tax events in 1988 and 2012. These fluctuations had reduced investor's confidence in making profits from long-term investment in mutual funds by either LS method or DCA method.

The debate on the adoption of LS method or DCA method in mutual fund investment has long existed in academic and practical evidence [2]-[5], [7]-[9]. The case company proposed a compound strategy which combines two methods in mutual fund investment for increasing their customers' confidence on investment. The strategy has successfully attracted investors' attention in Taiwan and promoted the net asset scale of mutual fund of the case company as the third rank among domestic mutual fund companies. The purpose of this research is to conduct a simulation analysis of the compound strategy by back-testing historical data, which covers the major financial events occurred in the past. We will compare the results with the following four benchmarks: 1) TAIEX index performance, 2) the performance of LS investing approach in source-fund (defined in Section II), 3) the performance of LS investing approach in sub-fund (defined in Section III), and 4) the performance of DCA approach for sub-fund during the same investment period.

The organization of this paper is as follows. Section II will review the relevant research on the issue. We introduce the compound strategy and simulation specification of such strategy in Section III. Section IV will present simulation results and make a comparison with four benchmarks. Finally, we will make some concluding remarks in Section V.

\section{LITERATURE REVIEW}

The debate between dollar-cost averaging (DCA) approach and lump-sum (LS) investing approach has existed for a long time [4]. DCA approach has merits of diversifying timing risk and averaging costs of investment for risk aversion (conservative) investors [3]. However, some of previous research proposed that DCA demonstrated inferior return than LS approach [2], [10]. Ref. [7] surveyed the performance of LS approach, DCA approach and value average approach in terms of Sharpe ratio, Sortino ratio and Upside Potential ratio metrics. Their findings also confirmed that DCA cannot outperform the other approaches in terms of the aforementioned performance metrics. However, it is appropriate for investors who would like to develop themselves savings discipline.

Pye [11] posited that although DCA was not the best investing approach for maximizing individual utility, investors could avoid the loss incurred from wrong timing if they adopted LS approach. Therefore, from the view of minimized regret, DCA was still the best investing approach.

Kahneman and Tversky [12] proposed the "Prospect Theory" to explain investors' behavior. They indicated that investors would become conservative when they made profits; however, as they suffered loss, they would seek risk with the hope to recover from loss. That means investors' attitude toward risk are different between profit stage and loss stage. So they may suffer regret torment as their investment decision is incorrect, from this view, they may prefer DCA to avoid the regret.

In terms of preceding decision theories, DCA approach has successfully attracted conservative investors' adoption and has become popular in personal finance plan.

Some research stated that DCA cannot be posited as inferior performance because context factors should be considered in the analysis [3]. Luskin [3] found that LS investing outperformed DCA roughly two-thirds of the time on a nominal return basis. The likelihood of DCA outperformance over LS investing is a function of the cyclically adjusted price-to-earnings (CAPE) ratio at the beginning of the investment period, with higher CAPE ratios linked to DCA outperformance.

The view point of situation (context) should be considered in evaluation of investment strategy to obtain more insights about feasibility of strategy. Therefore, this research will evaluate the investment strategy under various scenarios with consideration of market contexts.

\section{Method AND DATA SET}

The case company was founded in June, 1997. Now it has been ranked the third in domestic mutual fund companies with $5.76 \%$ of market share of mutual funds. Its business covers mutual funds, private funds and asset management, the scale of which is shown in Fig. 2.

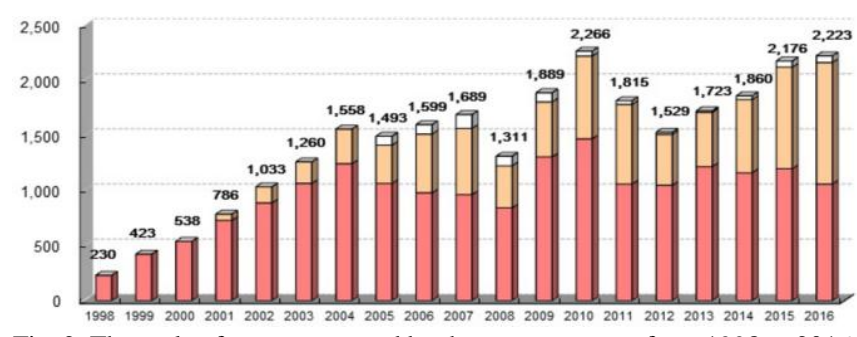

Fig. 2. The scale of assets managed by the case company from 1998 to 2016 (Orange bar: mutual fund; Earth yellow bar: asset management; White bar: private fund. All are denominated in NT\$ billion).

(Source: http://www.sitca.org.tw)

The data period was from $2002 / 8 / 21$ to $2015 / 3 / 10$, in which TAIFEX index was in the range of 4,887 to 9,536 . Several big events occurred during this period, including "one country on each side" argument proposed by ruling DPP (Domestic Progress Party) government which touched sensitive nerves between Taiwan and Mainland China in 2002, president assassination event in 2004, sub-prime financial tsunami in 2008-2009, bond crisis in Europe in 2010, reinstating capital gain tax in 2012, which may be considered to cover enough major events in Taiwan.

The compound strategy improves the conventional dollar-cost averaging (DCA) method which is executed by periodically (usually monthly) transferring money in bank accounts to purchase mutual funds to diversify timing of investments. In the compound strategy of the case company, the bank account is replaced by a source-fund which is 
considered as a mutual fund with low risk characteristic, such as global bond fund and balanced fund. After determining a source-fund which is invested by lump-sum (LS) investing approach, investors can choose a sub-fund or a set of sub-funds which have negative correlation or low correlation with the source-fund to execute DCA method. The preceding sub-fund usually has a higher volatility and should be set up a take-profit point as redemption timing. The money from redemption of sub-fund is transferred back to invest in source-fund. Such design is a dynamic bi-directional investment portfolio, which could benefit under bull market or bear market conditions by setting up both conservative (source-fund) and active (sub-fund) investment positions.

The compound strategy is developed by a source-fund and a sub-fund, both of which are selected from mutual funds raised by the case company. The source-fund is a global bond fund whose investment targets are global bond markets. It was raised since 2002/8/2 and its asset scale was NT\$ 933 million on 2015/5/29. The sub-fund may be one of the four domestic stock funds whose investment targets are domestic stock markets, summarized as Table I. The sub-fund must have negative correlation with source-fund or low correlation with source-fund. The correlation table is listed in Table II

\begin{tabular}{|c|c|c|c|c|}
\hline Sub-Fund & Set-up Date & $\begin{array}{l}\text { Scale of } \\
\text { Fund on } \\
2015 / 5 / 29 \\
\text { (NT\$ mil) }\end{array}$ & Type & $\begin{array}{l}\text { Benchmark } \\
\text { Index }\end{array}$ \\
\hline Fuh-Hwa & $1998 / 1 / 23$ & 2,225 & Equity & TAIEX \\
\hline $\begin{array}{l}\text { Digital } \\
\text { Economics }\end{array}$ & $2000 / 5 / 10$ & 6,376 & Equity & Electronics \\
\hline High Growth & 1998/10/17 & 2,533 & Equity & TAIEX \\
\hline Small Firm & $2001 / 4 / 3$ & 2,549 & Equity & TAIEX \\
\hline
\end{tabular}

TABLE II: CORRELATION TABLE* OF THE FIVE MUTUAL FundS

\begin{tabular}{llllll}
\hline \hline Sub-Fund & FH & HG & DE & SF & GB \\
\hline Fuh-Hwa (FH) & -- & 0.91 & 0.91 & 0.90 & -0.05 \\
High Growth (HG) & 0.91 & -- & 0.99 & 0.94 & -0.06 \\
$\begin{array}{l}\text { Digital Economics } \\
\text { (DE) }\end{array}$ & 0.91 & 0.99 & -- & 0.94 & -0.06 \\
Small Firm (SF) & 0.9 & 0.94 & 0.94 & -- & -0.04 \\
Global Bond (GB) & -0.05 & -0.06 & -0.06 & -0.04 & --
\end{tabular}

* The correlation coefficients are computed during the period between 2002/8/21 and 2015/3/10.

The simulation process is shown as follows:

1) Specify the source-funds and sub-funds which have negative or low correlation with each other. The specification of source-fund and sub-fund in the simulation are summarized in Table III.

2) Set the investment period. In this simulation study, 2002/8/21 2015/3/10 is set for covering various kinds of major events.

3) Set the amount of initial investment (i.e., Cost) in the source-fund. In this simulation analysis, it is set as NT\$1,200,000.

4) Plan how much will be invested in sub-fund per month. The parameter is set in the range of $\{100,000,80,000$, $70,000,60,000,50,000\}$

5) Choose the timing to invest in sub-fund (at which date per month should we invest in the sub-fund). The parameter is set in the range of $\{3,5,8,13,15,18,23,25,28\}$

6) Specify take-profit point for the sub-fund: Set the level of return on investment (ROI) for the redemption of mutual fund. The parameter is set in the range of $\{10 \%, 15 \%$, $20 \%, 23 \%, 25 \%$.

7) Simulation by back-testing.

8) Performance evaluation of the compound investment strategy under different market scenarios (ignoring taxes and transaction costs), including TAIEX index initially decreasing then increasing, TAIEX initially increasing then decreasing, and TAIEX in long-term bullish trend. TAIEX in long-term bearish trend is discarded because investors have no intention to invest mutual funds at this time.

9) Compare the performance of compound strategy with the following benchmarks: TAIEX index, LS investment in the source-fund, LS investment in the sub-fund, DCA in the sub-fund. All of the evaluations ignore taxes and transaction costs.

TABLE III: SIMULATION SPECIFICATION

\begin{tabular}{|c|c|c|c|}
\hline Fund & Choice & $\begin{array}{l}\text { Amount of Investment } \\
\text { (NT\$) }\end{array}$ & $\begin{array}{l}\text { Investment } \\
\text { Period }\end{array}$ \\
\hline Source-fund & $\begin{array}{l}\text { Global } \\
\text { Bond (GB) }\end{array}$ & $1,200,000$ & $\begin{array}{l}2002 / 8 / 21 \sim \\
2015 / 3 / 10\end{array}$ \\
\hline Sub-fund* & $\begin{array}{l}\text { Digital } \\
\text { Economics } \\
\text { (DE) }\end{array}$ & $\begin{array}{l}\text { Choosing one of the } \\
\text { following amount per } \\
\text { period in each } \\
\text { simulation: } 100,000 \text {, } \\
80,000 \text {, } \\
70,000 \text {, } \\
60,000 \text {, } \\
50,000\end{array}$ & $\begin{array}{l}2002 / 8 / 21 \sim \\
2015 / 3 / 10\end{array}$ \\
\hline
\end{tabular}

The performance metrics in the simulation analysis are listed and defined as follows.

- Cumulative $\mathrm{ROI}=$ cumulative profit during the investment period/total cost (initial investment)

- Standard deviation of annual ROI: standard deviation of annual return on investment during the investment period

- Max rise: max rise percentage of cumulative ROI during the investment period, which shows the optimistic performance during this period.

- Max decline: max decline percentage of cumulative ROI during the investment period, which shows the pessimistic performance during this period.

- Average risk per unit of ROI = standard deviation of annual ROI/annual ROI during the investment period

\section{RESUlTS AND DISCUSSION}

\section{A. Market Scenario Analysis}

The market situation covers the following three scenarios. The performance metrics are shown in Table IV-VI and Fig. 3-5.

- Initially decreasing then increasing (see Fig. 3., during the period of 2008/5/1 2010/5/1)

The simulation results (Table IV) show that the cumulative ROI of compound strategy is $36.54 \%$, which is higher than the cumulative ROI of TAIEX index (-11.28\%) during the same 
investment period. The max decline percentage is $-6.91 \%$, which is also better than $-54.37 \%$ of TAIEX index. In comparison with lump sum (LS) investment strategy in either source-fund or sub-fund, the compound strategy outperforms them; the former is $12.14 \%$, and the latter is $4.51 \%$. In comparison with dollar-cost averaging method (DCA) in sub-fund, the compound strategy is still better than the performance of the DCA method (31.31\%). The aforementioned information shows that the performance of compound strategy in this stock market scenario is better than the performance of TAIEX, LS method, and DCA method.

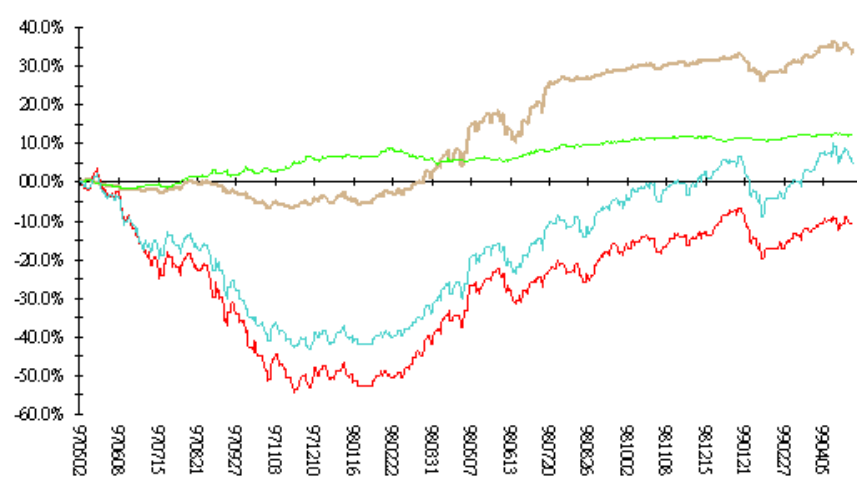

Fig. 3. Comparison of Cumulative ROI during the simulation period from 2008 to 2010. (X-axis: Date; Y-axis: Cumulative ROI; Blue line: sub-fund; Hazel line: compound strategy; red line: TAIEX; Green line: source-fund).

- Initially increasing then decreasing (see Fig. 4., during the period of 2002/8/21 2008/11/21)

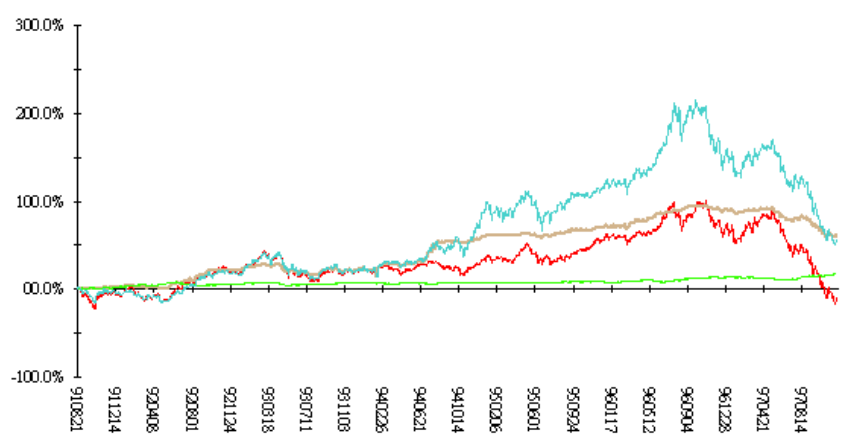

Fig. 4. Comparison of Cumulative ROI during the simulation period from 2002 to 2008. (X-axis: Date; Y-axis: Cumulative ROI; Blue line: sub-fund; Hazel line: compound strategy; red line: TAIEX; Green line: source-fund).

The simulation results (Table V) show that the cumulative ROI of compound strategy is $62.56 \%$, which is higher than the cumulative ROI of TAIEX index $(-8.88 \%)$ during the same investment period. The max decline percentage is $-0.56 \%$, which is also better than $-21.23 \%$ of TAIEX index. In comparison with LS investment strategy in either source-fund or sub-fund, the compound strategy outperforms them; the former is $18.03 \%$, and the latter is $57.92 \%$. In comparison with dollar-cost averaging method (DCA) in sub-fund, the compound strategy is still better than the performance of the DCA method (1.74\%). The aforementioned information shows that the performance of compound strategy in this stock market scenario is better than the performance of TAIEX, LS method, and DCA method.

- Long-term bullish trend (see Fig. 5., during the period of 2002/8/21 2015/3/10)

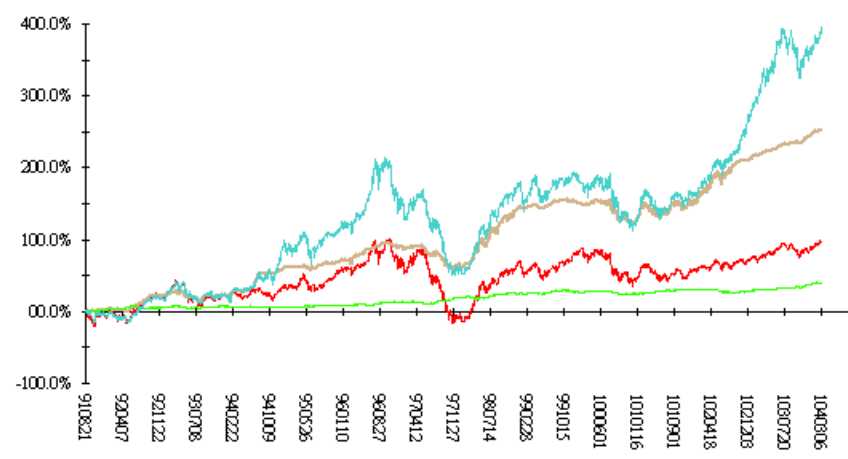

Fig. 5. Comparison of Cumulative ROI during the simulation period from 2002 to 2015. (X-axis: Date; Y-axis: Cumulative ROI; Blue line: sub-fund; Hazel line: compound strategy; red line: TAIEX; Green line: source-fund).

The simulation results (Table VI) show that the cumulative ROI of compound strategy is $254.66 \%$, which is higher than the cumulative ROI of TAIEX index $(95.11 \%)$ during the same investment period. The max decline percentage is $-0.56 \%$, which is also better than $-21.23 \%$ of TAIEX index. In comparison with LS investment strategy in source-fund, the compound strategy outperforms LS in source-fund (40.85\%); however, it cannot outperform LS in sub-fund (392.67\%). In comparison with the DCA approach in sub-fund, the compound strategy is better than the performance of the DCA method $(154.45 \%)$. The aforementioned information shows that the performance of compound strategy in this stock market scenario is better than the performance of TAIEX, LS method in source-fund, and DCA method, whereas it cannot outperform LS in sub-fund in the long-term bullish trend scenario of stock market.

TABLE IV: PERFORMANCE METRICS UNDER THE SCENARIO OF TAIEX INITIALLY INCREASING THEN DECREASING (UNIT: \$NT)

\begin{tabular}{llllll}
\hline \hline Strategy & Initial Investment & Ending Value & Profit & Cumulative ROI & Max Rise \\
& & & Max Decline & $-6.91 \%$ \\
Compound & $1,200,000$ & $1,599,263$ & 399,263 & $36.54 \%$ & $36.54 \%$ \\
TAIEX & $8,963.63$ & $7,952.17$ & $-1,011.46$ & $-11.28 \%$ & $3.70 \%$ \\
LS in Source-fund & 11.2198 & 12.5815 & 1.3617 & $12.14 \%$ & $12.61 \%$ \\
LS in Sub-fund & 17.97 & 18.78 & 0.81 & $4.51 \%$ & $-1.70 \%$ \\
DCA & 480,000 & 630,288 & 150,288 & $31.31 \%$ & $-43.96 \%$ \\
\hline \hline
\end{tabular}

Ps. Take-profit point: $23 \%$

TABLE V: PERFORMANCE METRICS UNDER THE SCENARIO OF TAIEX INITIALLY INCREASING THEN DECREASING (UNIT: \$NT)

\begin{tabular}{ccccccc}
\hline \hline Strategy & Initial Investment & Ending Value & Profit & Cumulative ROI & Max Rise & Max Decline \\
\hline Compound & $1,200,000$ & $1,950,728$ & 750,728 & $62.56 \%$ & $95.08 \%$ & $-0.56 \%$ \\
TAIEX & $4,887.79$ & $4,453.75$ & -434.04 & $-8.88 \%$ & $100.70 \%$ & $-21.23 \%$ \\
LS in Source-fund & 9.9954 & 11.7972 & 1.8018 & $18.03 \%$ & $18.20 \%$ & $-0.12 \%$ \\
LS in Sub-fund & 6.82 & 10.77 & 3.95 & $57.92 \%$ & $214.52 \%$ & $-15.10 \%$ \\
DCA & 750,000 & 763,050 & 13,050 & $1.74 \%$ & $1.74 \%$ & $-11.20 \%$ \\
\hline \hline
\end{tabular}

Ps. Stop-profit point: $23 \%$ 


\section{B. Simulation Analysis of Parameter Set Composed of} Periodic Investment Amount of DCA and Take-profit Point

Table VII shows that the level of periodic investment amount of DCA has a positive correlation with annual ROI. Table VII also demonstrates that the higher the level of Take-profit point, the higher the annual ROI. It shows that if an investor is aggressive and seeking for high return, then he or she could increase his/her deduction amount per month in terms of annual ROI performance measure. Table VIII shows that if investors are conservative (risk avoidance), in terms of standard deviation of annual ROI, they should reduce the deduction amount per month.

TABLE VI: PERFORMANCE METRICS UNDER THE SCENARIO OF TAIEX IN LONG-TERM BULLISH TREND (UNIT: \$NT)

\begin{tabular}{cllllll}
\hline \hline Strategy & Initial Investment & Ending Value & Profit & Cumulative ROI & Max Rise & Max Decline \\
\hline Compound & $1,200,000$ & $4,255,885$ & $3,055,885$ & $254.66 \%$ & $254.66 \%$ \\
TAIEX & $4,887.79$ & $9,536.53$ & $4,648.74$ & $95.11 \%$ & $100.70 \%$ \\
LS in Source-fund & 9.9954 & 14.0781 & 4.0827 & $40.85 \%$ & $40.85 \%$ \\
LS in Sub-fund & 6.82 & 33.6 & 26.78 & $392.67 \%$ & $396.19 \%$ & $-21.23 \%$ \\
DCA & $1,500,000$ & $3,816,750$ & $2,316,750$ & $154.45 \%$ & $154.45 \%$ \\
\hline \hline
\end{tabular}

Ps. Take-profit point: $23 \%$

TABLE VII: ANNUAL ROI BY COMPOUND STRATEGY SIMULATIONED IN PARAMETER SETS

\begin{tabular}{cccccc}
\hline $\begin{array}{c}\text { Take-profit } \\
\text { Point of }\end{array}$ & \multicolumn{5}{c}{ Periodic Investment Amount (Unit: NT\$) } \\
Sub-fund & 100,000 & 80,000 & 70,000 & 60,000 & 50,000 \\
\hline $10 \%$ & $6.97 \%$ & $6.63 \%$ & $6.31 \%$ & $6.01 \%$ & $5.51 \%$ \\
$15 \%$ & $9.15 \%$ & $8.42 \%$ & $8.03 \%$ & $7.82 \%$ & $7.04 \%$ \\
$20 \%$ & $10.11 \%$ & $9.58 \%$ & $9.14 \%$ & $8.79 \%$ & $8.18 \%$ \\
$23 \%$ & $11.47 \%$ & $10.89 \%$ & $10.60 \%$ & $10.02 \%$ & $9.14 \%$ \\
$25 \%$ & $11.76 \%$ & $11.52 \%$ & $10.92 \%$ & $10.23 \%$ & $9.34 \%$ \\
\hline
\end{tabular}

Ps.: The strategy is executed by lump sum investing NT\$1,200,000 in source-fund and dollar-cost averaging investment in sub-fund by setting the date of deduction on $15^{\text {th }}$ of each month.

\section{Date of Periodic Deduction}

Table IX shows that setting $15^{\text {th }}$ of each month as the date of deduction for the compound strategy has the highest annual ROI. Because of higher annual ROI, its standard deviation is also higher than some of the other dates. However, in terms of average risk performance index, it is a relatively acceptable date. The value of 1.48 is the second best one (only $25^{\text {th }}$ is lower than $15^{\text {th }}$.) The poorest choice is $28^{\text {th }}$. The possible reason is that securities investment trust companies have to publish their performance of mutual funds monthly in Taiwan, therefore, managers of mutual fund have motivation to increase asset value of fund by the end of each month (or each quarter or each year) with some tactics, such will make investors buying a unit of mutual fund at higher price when they set the end of each month as their deduction date.

TABLE VIII: ANNUALIZED STANDARD DEVIATION OF ROI BY COMPOUND STRATEGY SIMULATIONED IN PARAMETER SETS

\begin{tabular}{cccccc}
\hline $\begin{array}{c}\text { Take-profit } \\
\text { Point of } \\
\text { Sub-fund }\end{array}$ & 100,000 & 80,000 & 70,000 & 60,000 & 50,000 \\
\hline $10 \%$ & $14.31 \%$ & $12.27 \%$ & $10.92 \%$ & $9.39 \%$ & $8.02 \%$ \\
$15 \%$ & $17.66 \%$ & $14.87 \%$ & $13.54 \%$ & $11.83 \%$ & $10.03 \%$ \\
$20 \%$ & $19.60 \%$ & $16.82 \%$ & $15.27 \%$ & $13.49 \%$ & $11.49 \%$ \\
$23 \%$ & $20.75 \%$ & $17.38 \%$ & $15.70 \%$ & $13.66 \%$ & $11.46 \%$ \\
$25 \%$ & $21.04 \%$ & $18.25 \%$ & $16.42 \%$ & $14.27 \%$ & $11.96 \%$
\end{tabular}

Ps.: The strategy is executed by lump-sum investing NT\$ 1,200,000 in the source-fund and dollar-cost averaging of the sub-fund is monthly deduced on 15 th of each month.
TABLE IX: SiMULATION INVESTMENT PERFORMANCE IN TERMS OF DATE OF

\begin{tabular}{cccccc}
\multicolumn{5}{c}{ DEDUCTION } \\
\hline \hline Date & $\begin{array}{c}\text { Annual } \\
\text { SD }\end{array}$ & Annual ROI & $\begin{array}{c}\text { \# of } \\
\text { take-profit }\end{array}$ & Max Decline & Avg Risk ${ }^{*}$ \\
\hline $3^{\text {rd }}$ & $15.78 \%$ & $10.56 \%$ & 7 & $0.28 \%$ & 1.49 \\
$5^{\text {th }}$ & $15.72 \%$ & $10.46 \%$ & 7 & $0.03 \%$ & 1.50 \\
$8^{\text {th }}$ & $15.61 \%$ & $10.35 \%$ & 7 & $0.06 \%$ & 1.51 \\
$13^{\text {th }}$ & $15.78 \%$ & $10.56 \%$ & 7 & $0.28 \%$ & 1.49 \\
$15^{\text {th }}$ & $15.70 \%$ & $10.60 \%$ & 6 & $0.56 \%$ & 1.48 \\
$18^{\text {th }}$ & $15.77 \%$ & $10.35 \%$ & 6 & $0.30 \%$ & 1.52 \\
$23^{\text {rd }}$ & $15.68 \%$ & $10.55 \%$ & 6 & $0.60 \%$ & 1.49 \\
$25^{\text {th }}$ & $15.08 \%$ & $10.37 \%$ & 6 & $0.28 \%$ & 1.45 \\
$28^{\text {th }}$ & $16.76 \%$ & $7.81 \%$ & 6 & $0.27 \%$ & 2.15
\end{tabular}

Ps. LS investing NT $\$ 1,200,000$ in source-fund with DCA method of NT\$70,000. The Take-profit point is $23 \%$.

*Average risk (i.e., Average risk per unit of ROI) = standard deviation of annual ROI/annual ROI during the investment period

\section{CONCLUSION}

This research evaluates the pros and cons of a compound investment strategy proposed by the case company in terms of several performance metrics by a set of simulation in different market contexts. In comparison with TAIEX index, lump sum investment method, and dollar-cost averaging investment method, the compound investment strategy can have the best performance under the following two scenarios (contexts) of stock market: TAIEX index initially decreasing then increasing, and TAIEX initially increasing then decreasing; however, it can only achieve the second best performance under the scenario of stock market in long-term bullish trend. In other words, this strategy can perform well in most of market contexts, especially appropriate for the investment duration in which the trend of stock market contains turning points. If a market is highly confirmed to be a bullish market, then lump-sum investment strategy has the best performance; however, it might face higher volatility (risk).

This research conducted simulation analysis in terms of one source-fund and one sub-fund with a set of simulation parameters. Future research can extend the examination scope to further study the pros and cons of the compound strategy. More mutual fund alternatives could be included in the simulation scope, for example, mutual funds raised by other companies or other types of mutual funds can be considered in 
simulation scope to gain more insights about the performance of the compound strategy.

\section{REFERENCES}

[1] A. Srivastava and V. Kumar, "Performance evaluation of mutual fund: A study of reliance mutual fund," CLEAR International Journal of Research in Commerce \& Management, vol. 7, no. 3, pp. 77-82, Mar. 2016.

[2] R. E. Williams and P. W. Bacon, "Lump sum beats dollar-cost averaging," Journal of Financial Planning, vol. 6, no. 2, 1993.

[3] J. M. Luskin, "Dollar-cost averaging using the cape ratio: an identifiable trend influencing outperformance," Journal of Financial Planning, vol. 30, no. 1, pp. 54-60, Jan. 2017.

[4] M. S. Rozeff, "Lump-sum investing versus dollar-averaging," The Journal of Portfolio Management, vol. 20, no. 2, pp. 45-50, 1994.

[5] J. E. Grable and S. Chatterjee, "Another look at Lump-Sum versus dollar-cost averaging," Journal of Financial Service Professionals, vol. 69, no. 5, pp. 16-18, Sep. 2015.

[6] M. J. Brennan, F. Li, W. N. Torous et al., "Dollar cost averaging," Review of Finance, vol. 9, no. 4, pp. 509-535, 2005.

[7] K. B. Leggio and D. Lien, "An empirical examination of the effectiveness of dollar-cost averaging using downside risk performance measures," Journal of Economics and Finance, vol. 27, no. 2, p. 211, 2003.

[8] P. S. Marshall, "A statistical comparison of value averaging vs. dollar cost averaging and random investment techniques," Journal of Financial and Strategic decisions, vol. 13, no. 1, pp. 87-99, 2000.

[9] K. B. Leggio and D. Lien, "Does loss aversion explain dollar-cost averaging?" Financial Services Review, vol. 10, no. 1, pp. 117-127, 2001.
[10] A. Shtekhman, C. Tasopoulos, and B. Wimmer, "Dollar-cost averaging just means taking risk later," Vanguard Research, 2012.

[11] G. Pye, "Minimax policies for selling an asset and dollar averaging," Management Science, vol. 17, no. 7, pp. 379-393, 1971.

[12] D. Kahneman and A. Tversky, "Prospect theory. An analysis of decision making under risk," DTIC Document, 1977.

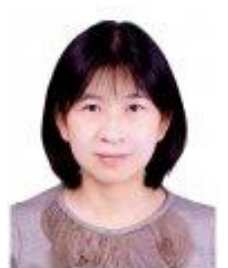

Jen-Ying Shih received her $\mathrm{PhD}$ and master's degree in business administration from National Taiwan University, Taiwan. She has been teaching at National Taiwan Normal University since August, 2008 and became an associate professor in 2012. Her research interests focus on data mining in finance and marketing and knowledge management. She has published papers in international academic journals and international conference proceedings in information and management areas.

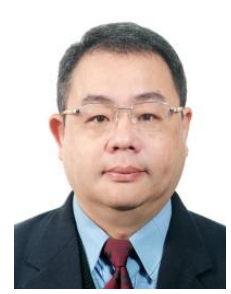

Wei-Cheng Chiang is a senior vice president of Fuh-Hwa Securities Trust Ltd. He received his EMBA degree from College of Management, National Taiwan Normal University. He has been in Fuh-Hwa Securities Trust Ltd. for twenty years and has much professional experience in mutual fund markets, and now he is in charge of financial planning services of Fuh-Hwa Securities Trust Ltd. His research interests focus on financial planning and investment strategy. 